\title{
Seven Social Performance Scales for the California Psychological Inventory
}

\author{
John A. Johnson \\ Department of Psychology \\ Pennsylvania State University
}

\begin{abstract}
This article describes the construction and validation of 7 scales for the California Psychological Inventory (Gough, 1975, 1987) based on a socioanalytic interpretation of the Five-Factor Model. The scale construction differed from traditional rational and empirical approaches in that it regarded responses to personality items as speech acts-skilled performances that create an effect on an audience. Expected group differences across 10 samples (total $N=763$ ) and relations with other personality inventory scores, vocational choice, educational achievement, drug use and anti-social behavior, job performance, and observer ratings supported the construct validity of the scales.
\end{abstract}

This article describes the construction of seven scales for the California Psychological Inventory (CPI; Gough, 1975, 1987) designed to assess social performance. This set of scales, constructed in the late 1970s, prefigured the development of several personality inventories based on the Five Factor Model (FFM; McCrae \& John, 1992), including the Hogan Personality Inventory (HPI; Hogan, 1986) and NEO-PI (Costa \& McCrae, 1985). Previous publications (Hansson, Hogan, Johnson, \& Schroeder, 1983; Hogan, Carpenter, Briggs, \& Hansson, 1985; Johnson, 1983) have mentioned these scales only in passing. By detailing the unique strategies underlying the construction of these CPI scales, this article clarifies the conditions under which FFM-based inventories such as the HPI and NEO-PI successfully predict real-life performance.

The article is organized according to the four-step model of construct validation, called conceptual analysis, used by Gough (1987) to explicate the meaning of CPI scale scores. The article does not use the traditional method and results sections, although it does conclude with an overall discussion of the findings.

Requests for reprints should be sent to John A. Johnson, Department of Psychology, Penn State DuBois Campus, College Place, DuBois, PA 15801.E-mail: j5j@psu.edu. 
Gough's first conceptual analytic step reviews the measurement objectives and specific methods used to construct the scales. The second step examines the themes within the manifest content of the items. The third step assesses relations between scale scores and other established psychological measures and compares scores from subgroups that have distinctive psychological features. This third step aims to establish expected relations with other variables (e.g., a new measure of intellectuality should correlate with similar measures of intellect; high school honor students should score higher on the measure than dropouts) and uncover unexpected relations that further clarify the meaning of scores. The fourth step contrasts the impressions made by high and low scorers on interviewers or acquaintances.

\section{STEP 1: MEASUREMENT OBJECTIVES AND METHODS}

\section{Speech Act Framework}

The scale construction procedure in this study differed from the traditional empirical and rational procedures in that it considered responses to personality items as perlocutionary speech acts (Searle, 1969). The speech act perspective suggests that word-meaning is created by the intended (illocutionary) and actual (perlocutionary) effects of words on a speaker's audience. This contrasts with the older, referential view, that words derive meaning from their correspondence to the state of affairs to which they refer. From a speech act perspective, to determine what a "True" or "False" response to a personality item means (i.e., what the item measures), one needs to assess correctly the item response's intended effect (illocution) and actual effect (perlocution) on the audience who observes the response (cf. Mills \& Hogan, 1978; Rorer, 1990, pp. 713-715).

\section{Measurement Objectives Within the Speech Act Framework}

Working from this speech act perspective, Hogan and Johnson (1979) independently imagined the effect that endorsement/denial would have on a "generalized other" (Mead, 1934) for every item on the 480-item CPI (Gough, 1975). Their measurement objective was to discern how an item response would affect observers' impressions of the respondent along seven dimensions of Hogan's (1983) socioanalytic theory: Sociability, Ambition, Likeability, Prudence, Adjustment, Intellectance, and Ego Control. The seven dimensions were inspired by the "adequate taxonomy" proposed by Norman (1963), today called the FFM (McCrae \& John, 1992). Socioanalytic theory suggested, however, subdividing two of the five major domains of the FFM into two narrower subdomains (see Hogan \& Johnson, 1979,1981 , for the justification). Seven sets of items judged by both Hogan and
Johnson as effective speech acts for creating impressions on an audience constituted initial "core scales" for further scale development.

\section{Comparison/Contrast With Rational Method}

Similarities and differences between this portion of the scale development procedure and the traditional rational scale development procedure should be noted. The rational approach identifies items whose content matches the construct being measured. It also assumes that a valid response must correspond or refer to the actual state of affairs (this is the referential view of meaning). For example, the content of "I am smarter than most people" plainly relates to the Intellect construct. If, in the actual state of affairs, a respondent is smarter than most people, a "True" response would be considered valid and a point awarded on the Intellect scale.

From a speech act perspective, "I am smarter than most people" would be considered a good Intellect item only to the degree that an audience would consider a person who endorsed this item as someone possessing high intellect. For many individual item responses, which are decontextualized and therefore not subject to discounting or falsification, an audience will likely accept the response at face value. Social etiquette tells us to accept performances as valid until actors give us reasons to discount their illocutions (Hogan, 1976). Therefore, the speech act and rational approaches will identify many of the same items as potentially good items for a scale.

The speech act approach goes beyond the rational approach, however, in several ways. First, it does not always follow the rationalist predilection for taking responses at face value. For example, consider the item, "I am smarter than most people think." Superficially, this item looks similar to the previous Intellect item and might therefore be considered a good Intellect item by a rational scale-developer. But a moment's reflection leads to the realization that someone who says things like "I am smarter than most people think" is defensively trying to counteract a reputation for low intelligence. A new observer might therefore be just as likely to join the social consensus and regard someone who endorses this item an unintelligent. (In fact, although this experimental item for the HPI was eventually dropped, it correlated negatively - as expected-with perceived intelligence.)

A second rationalist assumption regarded as unnecessary by the speech act perspective is that a valid response must reflect the actual state of affairs. Hyperbole and exaggeration do not reflect actual states of affairs, but nevertheless communicate valid information about personality (Johnson \& Horner, 1990). "I am never late for meetings" cannot be literally true for most people (because of the absolute qualifier, "never"), but a very conscientious person should nevertheless endorse this item to create the appropriate impression of conscientiousness.

Finally, although semantic knowledge is sufficient for determining the meaning of rationally constructed personality items, assessing an item response's perlocution 
requires sociolinguistic or pragmatic knowledge (Grundy, 1995). Sociolinguistic or pragmatic rules, mutually understood by speakers and listeners, allow for inferences beyond the narrow semantic meaning of a sentence. For example, consider someone who remarks, "When I get bored I like to stir up some excitement" (CPI Form 462, item number 77; Gough, 1986). A narrowly semantic interpretation of the remark is that the speaker creates excitement when bored. McCrae, Costa, and Piedmont (1993) consequently asserted that this item reflects excitement-seeking. However, those who are familiar with the context of the delinquent subculture will recognize "stir up some excitement" as a euphemism used by delinquents to describe doing something illegal. Therefore, the perlocution of this remark is that the speaker is a delinquent, a troublemaker.

\section{Enhancing the Validity of the Speech Act Approach}

Interpreting personality item responses as speech acts requires an imaginative rendering of a respondent's thoughts, and the earlier examples demonstrate that this can be a complex, subtle, and subjective process. Some psychologists might consider the process too difficult and fraught with error. The empirical scale-construction strategy (Meehl, 1945) flatly denies that psychologists can fathom the psychological dynamics underlying item responses. Hogan and Johnson (1979) understood this concern, which is why they began with independent judgments of CPI items' perlocutions and retained only those items upon which they agreed. This procedure produced seven "core" scales, each containing 5 to 12 items clearly related to the socioanalytic dimensions. For the next step in scale development, Hogan and Johnson followed more traditional psychometric procedures to enhance the validity of their scales.

Two archival data sets from the Institute of Personality Assessment and Research at Berkeley were used to identify additional items for the core scales to increase scale reliability. The samples ( 45 male research scientists-see Gough \& Woodworth, 1960; and 66 male engineers-see Dunnette, Wernimont, \& Abrahams, 1964) were recommended by Gough (personal communication, 1979) for scale development purposes. Scores on the core scales were calculated for all individuals in the two samples and then correlated with their responses on all remaining items not appearing on a core scale. Items that were significantly correlated in both samples with the core scales were added to each scale. This procedure identified items whose socioanalytic perlocutions are more subtle than the items on the core scales. A list of all item numbers can be found in the appendix of this article.

Table 1 summarizes some basic characteristics of the final scales. This table indicates the total number of items on each scale, the mean and standard deviation for 10 samples combined $(N=763$, described in Table 2), Kuder-Richardson reliability estimates for the scale development sample and the sample of college
TABLE 1

Characteristics of Socioanalytic Scales for the California Psychological Inventory

\begin{tabular}{|c|c|c|c|c|c|}
\hline Scale & Items & $M^{\mathrm{a}}$ & $S D^{\mathrm{a}}$ & Reliability $^{\mathrm{b}}$ & $\begin{array}{l}\text { Item With Highest } \\
\text { Item-Total Correlation }\end{array}$ \\
\hline Sociability & 23 & 12.5 & 4.4 & $.74 \quad .70$ & I like parties and socials. \\
\hline Ambition & 27 & 18.7 & 4.8 & $.82 \quad .81$ & $\begin{array}{l}\text { When I work on a committee I like } \\
\text { to take charge of things. }\end{array}$ \\
\hline Likeability & 21 & 14.0 & 3.2 & $.67 \quad .69$ & I often lose my temper. (R) \\
\hline Prudence & 22 & 13.3 & 3.7 & $.59 \quad .69$ & $\begin{array}{l}\text { Sometimes I rather enjoy going } \\
\text { against the rules and doing things } \\
\text { I'm not supposed to. (R) }\end{array}$ \\
\hline Adjustment & 28 & 20.8 & 5.1 & $.88 \quad .83$ & $\begin{array}{l}\text { I am embarrassed with people I do } \\
\text { not know well. (R) }\end{array}$ \\
\hline Intellectance & 24 & 16.6 & 3.0 & $.89 \quad .62$ & I read at least ten books a year. \\
\hline Ego Control & 21 & 12.7 & 3.6 & $.66 \quad .65$ & $\begin{array}{l}\text { I always see to it that my work is } \\
\text { carefully planned and organized. }\end{array}$ \\
\hline
\end{tabular}

Note. Items modified and reproduced by special permission of the Publisher, Consulting Psychologists Press, Inc., Palo Alto, CA 94303 from California Psychological Inventory ${ }^{\mathrm{TM}}$ by Harrison G. Gough. Copyright 1987 by Consulting Psychologists Press, Inc. All rights reserved. Further reproduction is prohibited without the Publisher's written consent.

${ }^{a}$ All 10 samples listed in Table 2 combined, $N=763$. ${ }^{b}$ First KR-20 coefficient is from derivation sample of research scientists and engineers, $N=111$; second coefficient is from college students (Sample 10 in Table 2), $N=237$.

students described in Table 2, and the item with the highest item-total correlation in the student sample.

\section{STEP 2: ITEM CONTENT}

Because the selection procedure began with items whose content was directly relevant to the seven socioanalytic dimensions, the themes in each scale are clearly related to these dimensions. Descriptions of the underlying construct and item content of the seven new CPI scales-CPI-Sociability, CPI-Ambition, CPI-Likeability, CPI-Prudence, CPI-Adjustment, CPI-Intellectance, and CPI-Ego Control ${ }^{1}$-are presented next.

'The actual, original scale names in the Hogan and Johnson (1979) article were Person-Thing Orientation, Assertiveness, Likability [sic], Prudence, Anxiety/Self-Esteem, Intellectance, and Ego Control. The evolution of some of the labels in socioanalytic theory (Hansson, Hogan, Johnson, \& Schroeder, 1983; Hogan, 1983; Hogan \& Johnson, 1981; Johnson, 1983) reflect for the most part preferences for new labels rather than reconceptualizations of the dimensions. Scale labels in this article are identical to the primary scale labels in the current Hogan Personality Inventory (Hogan \& Hogan, 1992) to reflect their common origin in socioanalytic theory. To distinguish the two sets of scales, the scales constructed from CPI items are prefaced in the text with the acronym "CPI-" and are identified in tables by the table headings. 
CPI-Sociability reflects simply a preference for being with people versus being alone. Liking people is one aspect of Factor I of the FFM (McCrae \& John, 1992). In the work world, the high end of sociability is related to careers concerned with managing or helping others, whereas the low end indicates an asocial orientation toward things and ideas (Holland, 1979). The content of most of the items on the CPI-Sociability scale concerns enjoying parties, participating in groups, and pursuing social interaction.

CPI-Ambition represents another aspect of FFM Factor I, specifically an energetic striving to impose one's will on the environment (Johnson \& Ostendorf, 1993; cf. White, 1959). CPI-Ambition items generally reflect two themes: (a) leading and influencing others, and (b) working hard.

CPI-Likeability, based on Factor II of the FFM, is viewed by socioanalytic theory as an unconscious strategy for garnering support from others by doing things that other people find pleasing (e.g., treating others with tolerance, kindness, care, and trust). Unlikable behavior, in contrast, manipulates others through irritation or intimidation. Positively scored CPI-Likeability items reflect a concern for others' feelings, whereas negatively scored items reveal anger and irritation toward others.

CPI-Prudence, related to FFM Factor III, is defined in socioanalytic theory as the wisdom to avoid risky, self-defeating behavior, especially the violation of social norms and expectations. Prudence was hypothesized to differentiate smart players who achieve status from delinquents and criminals who fail to achieve status. $\mathrm{CPI}-$ Prudence items reflect respect for authority and rules and avoidance of risks.

CPI-Adjustment, corresponding to Factor IV, is unique among FFM conceptions of the emotional stability domain in its emphasis on the social causes and consequences of emotional adjustment rather than the private experience of emotions (Johnson \& Ostendorf, 1993). Neuroticism in normal populations usually manifests itself as social anxiety (Lanning \& Gough, 1991); for this reason social anxiety was central to this conceptualization of this domain. Most CPI-Adjustment items concern poise and composure in social situations.

CPI-Intellectance, representing FFM Factor V, is a term Hogan (1983) borrowed from Welsh (1975), although Welsh spelled the term Intellectence. Intellectance describes an interpersonal style that causes others to describe a person as intelligent (Hogan, 1986). The content of CPI-Intellectance items pertains to competence, especially success in school, but also to broad interests in science, the arts, and world affairs.

CPI-Ego Control (after Block \& Block, 1980; see also Johnson \& Hogan, 1981; Laufer, Johnson, \& Hogan, 1981) describes the suppression of primary process (pace Freud) ideation. Because primary process includes impulses toward antisocial activities, Ego Control overlaps with Prudence (Factor III). Because primary process also includes imaginative and novel thinking, Ego Control was assumed to differentiate custodial persons who maintain the status quo from creative individuals who play the role of innovators in society (Johnson, 1983). That is, explorative, experience-seeking, innovative behavior does not necessarily involve destructive, antisocial behavior. The low end of Ego Control is similar to the Openness to Experience interpretation of Factor V (McCrae \& Costa, 1985). Ego Control is therefore a blend of Factors III and V (III+V- in Johnson and Ostendorf's, 1993, terminology), and consequently the content of CPI-Ego Control items is diverse. About one-third of the items describe a preference for planning and organization over spontaneity. Other items refer to dislike of uncertainty, asymmetry, ambiguity, and surprises.

\section{STEP 3: RELATIONS WITH OTHER VARIABLES}

\section{Participants}

Participants were individuals who had completed the CPI in previous research studies; thus, a complete description of the participants can be found in the original sources. Table 2 provides a brief description of the samples used in the scale development.

\section{Measures and Analyses}

The participants' CPI protocols were rescored on the seven scales described earlier. Additional information —other test scores, observer ratings of personality, and job

TABLE 2

Data Sets Reanalyzed for this Study

\begin{tabular}{|c|c|c|c|}
\hline \multicolumn{2}{|c|}{ Number } & \multirow[b]{2}{*}{ Description } & \multirow[b]{2}{*}{ Reference } \\
\hline Male & Female & & \\
\hline 45 & & Research scientists & Gough \& Woodworth (1960) \\
\hline 66 & & Engineers & $\begin{array}{l}\text { Dunnette, Wernimont, } \\
\text { \& Abrahams (1964) }\end{array}$ \\
\hline 42 & 2 & $\begin{array}{l}\text { Salespersons for an engineering } \\
\text { corporation }\end{array}$ & Hogan (1979) \\
\hline 46 & 3 & Baltimore County police officers & Johnson \& Hogan (1981) \\
\hline 99 & & Oakland City police officers & Hogan (1971) \\
\hline 70 & & Murderers & $\begin{array}{l}\text { Laufer, Johnson, \& Hogan } \\
\text { (1981) }\end{array}$ \\
\hline 49 & & Marijuana smokers & $\begin{array}{l}\text { Hogan, Mankin, Conway, \& Fox } \\
\text { (1970) }\end{array}$ \\
\hline 50 & & Principled nonsmokers & $\begin{array}{l}\text { Hogan, Mankin, Conway, \& Fox } \\
\text { (1970) }\end{array}$ \\
\hline 54 & & Phi Beta Kappas & Hogan \& Weiss (1974) \\
\hline 104 & 133 & College students from 2-year campus & Johnson \& Ostendorf (1993) \\
\hline
\end{tabular}


performance-was available for many of these cases. Relations between the new $\mathrm{CPI}$ scales and these other variables were calculated to further clarify the construct validity of the scales.

\section{Group Differences}

Group comparisons are contained in Table 3. The tenth sample is college students attending a 2-year campus located in Appalachia. Government statistics for the region surrounding the campus indicate severe economic depression, high rates of unemployment, one of the highest rates of drug and alcohol abuse in the nation, and one of the poorest support systems for children in the state. Consistent with the socioanalytic viewpoint, college students from this area score about .5 standard deviations below the overall mean on CPI-Likeability, CPI-Prudence, CPI-Adjustment, and CPI-Intellectance.

Socioanalytic theory suggests that sociability and ambition distinguish individuals who prefer to work with people from individuals who prefer to work with things and ideas (Johnson, 1983). As expected, the salespersons received the highest scores (among all groups with a known vocation) on CPI-Sociability and CPI-Ambition, whereas the engineers and scientists received the lowest scores. Agreeableness should differentiate individuals who treat others in a calm, even-handed manner from those who are hostile and aggressive; of the first nine groups, the Oakland police and murderers showed the highest and lowest scores on CPI-Likeability, respectively.

Because CPI-Prudence was designed to reflect respect for rules, one would predict the police to outscore the convicted murderers and marijuana smokers; they do by about 1 standard deviation. However, the highest CPI-Prudence scores are found for the Phi Beta Kappas; furthermore, the salespersons, scientists, and engineers all score above the mean of all samples. This confirms the socioanalytic view that prudence is related to high-level achievement and professional success.

Predictably, the murderers scored the lowest of the first nine groups on CPI-Adjustment. However, all of the student groups-including the Phi Beta Kappas-scored somewhat below the mean on this scale. This indicates that, relative to employed adults, college students present themselves as socially somewhat maladjusted.

The scientists had the highest score on CPI-Intellectance, whereas the murderers had one of the lowest scores. The two police groups also scored below the mean, not because they are unintelligent (see Hogan, 1971), but because the interpersonal style of the artist is not conducive to effective police performance (Johnson \& Hogan, 1981).

The low end of the CPI-Ego Control scale, like Gough's (1987) Self-Control scale, was designed to assess a type of "nondelinquent impulsivity" (p. 45). Laufer,

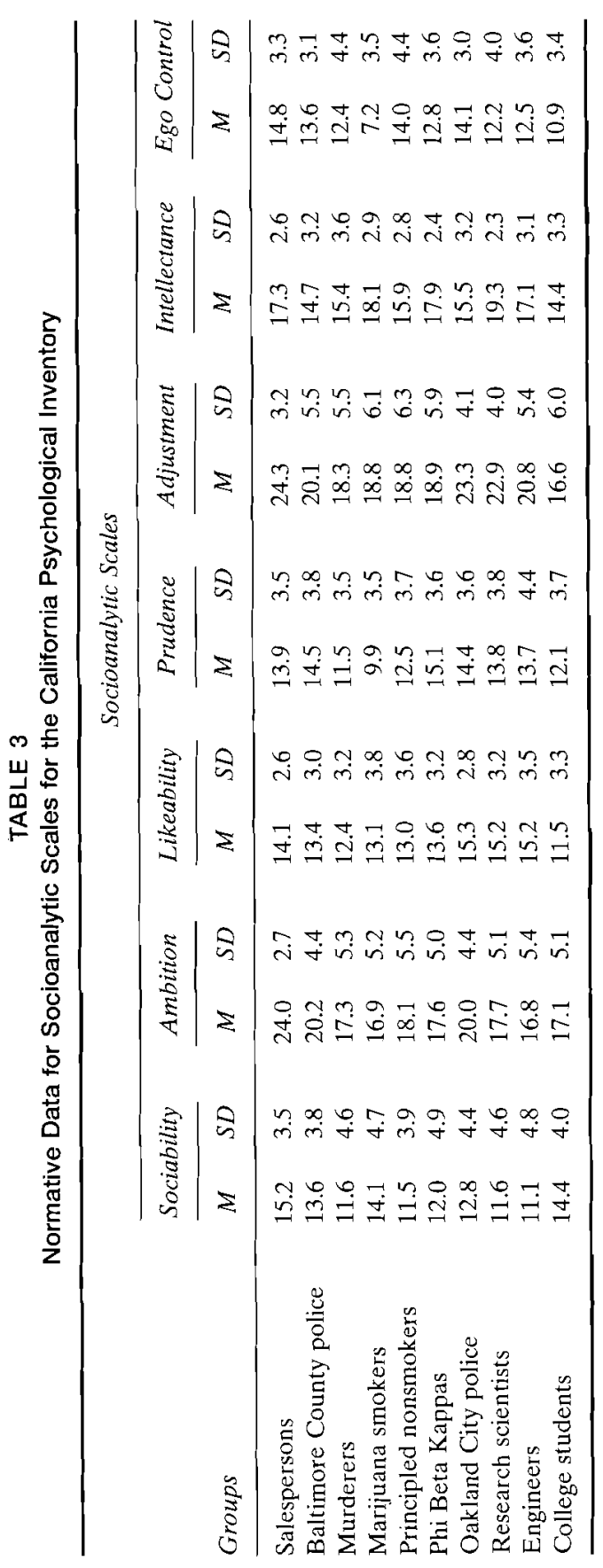


Johnson, and Hogan (1981) portrayed an individual with low ego control as uninhibited, freespirited, spontaneous, nonconforming, unfocused, pleasure-seeking, and sometimes even impetuous-but not risk-taking to the point of endangering lives or committing serious crimes. Like individuals "open to experience" (Costa \& McCrae, 1992), they enjoy novelty and variety. The group that best represents low ego control, the marijuana smokers, scored 1.5 standard deviations below the group mean, whereas the murderers scored right at the group mean on CPI-Ego Control (see also Laufer, Johnson, \& Hogan, 1981).

\section{Scale Intercorrelations}

The socioanalytic scales were inspired by the FFM (McCrae \& John, 1992). CPI-Sociability and CPI-Ambition represent Factor I; CPI-Likeability, Factor II; CPI-Prudence, Factor III; CPI-Adjustment, Factor IV; and CPI-Intellectance, Factor V. CPI-Ego Control represents a blend of the high end of Factor III and the low end of Factor V. Because the FFM contains five orthogonal dimensions, CPI-Sociability, CPI-Likeability, CPI-Prudence, CPI-Adjustment, and CPI-Intellectance should be relatively uncorrelated. CPI-Ambition, another aspect of Factor I, should correlate with CPI-Sociability, and CPI-Ego Control should correlate positively with CPI-Prudence and negatively with CPI-Intellectance.

Table 4 presents socioanalytic scale intercorrelations for two samples. Disregarding scales expected to correlate (CPI-Ambition with CPI-Sociability; CPI-Ego Control with CPI-Prudence and CPI-Intellectance), the mean absolute value of the correlations in the matrix is $r=.175$. This is less than the mean absolute value of the intercorrelations for the NEO-PI scales, $r=.20$ (Costa \& McCrae, 1992, Appendix F), which were explicitly designed to be statistically uncorrelated.

As expected, CPI-Ambition and CPI-Sociability correlated significantly in both samples, $r \mathrm{~s}=.33$ and .46 , as did CPI-Ego Control and CPI-Prudence, $r \mathrm{~s}=.47$ in both samples. Contrary to expectations, CPI-Ego Control and CPI-Intellectance were uncorrelated.

\section{Relations With Other Variables}

$C P I$. When new scales are developed for an inventory it is instructive to compare them to the existing scales for the inventory. Table 5 presents these correlations for two samples. Predictably, the new socioanalytic CPI-Sociability scale correlated highest with the standard CPI scale of the same name. CPI-Ambition correlated so strongly with Dominance that it might be regarded as essentially equivalent to that scale. CPI-Likeability correlated most strongly with Amicability, a new CPI scale designed by Gough explicitly to assess Factor II of the FFM.

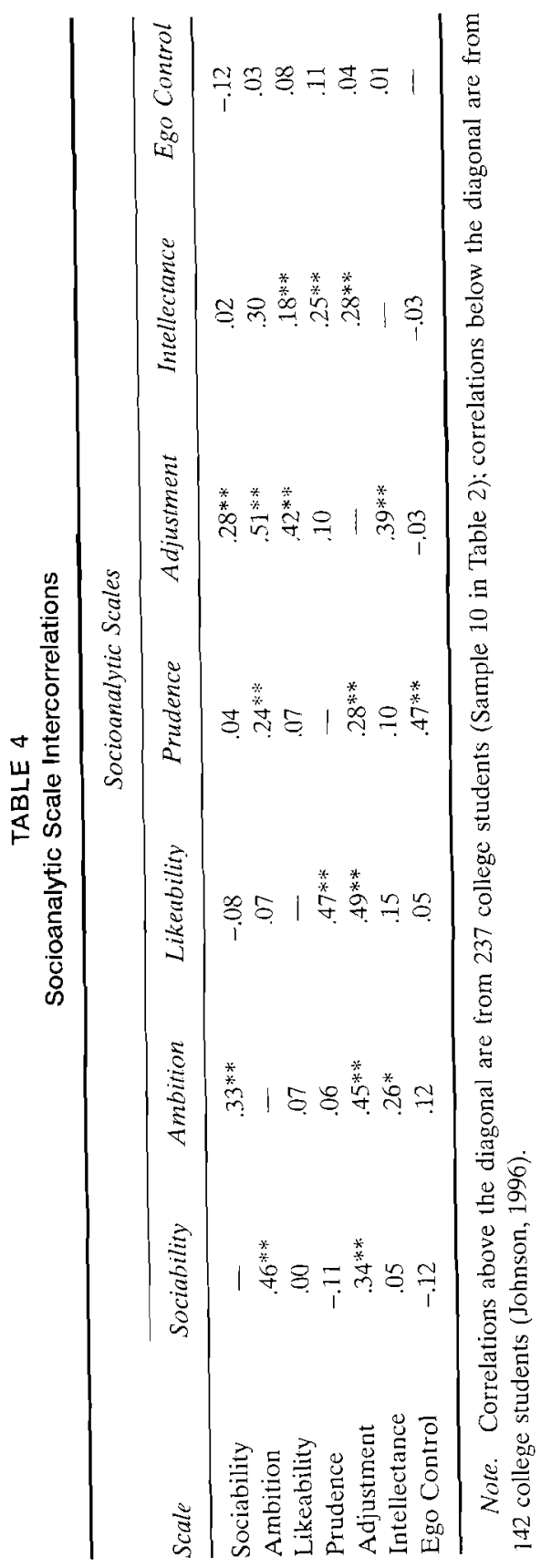


TABLE 5

Correlations Between Standard California Psychological Inventory (CPI) Scales and Socioanalytic Scales

\begin{tabular}{|c|c|c|c|c|c|c|c|c|c|c|c|c|c|c|}
\hline \multirow[b]{3}{*}{ CPI Scale } & \multicolumn{14}{|c|}{ Socioanalytic Scales } \\
\hline & \multicolumn{2}{|c|}{ Sociability } & \multicolumn{2}{|c|}{ Ambition } & \multicolumn{2}{|c|}{ Likeability } & \multicolumn{2}{|c|}{ Prudence } & \multicolumn{2}{|c|}{ Adjustment } & \multicolumn{2}{|c|}{ Intellectance } & \multicolumn{2}{|c|}{ Ego Control } \\
\hline & $l^{\mathrm{a}}$ & $2^{b}$ & $l^{\mathrm{a}}$ & $2^{\mathrm{b}}$ & $l^{\mathrm{a}}$ & $2^{\mathrm{b}}$ & $l^{\mathrm{a}}$ & $2^{\mathrm{b}}$ & $l^{\mathrm{a}}$ & $2^{b}$ & $1^{\mathrm{a}}$ & $2^{b}$ & $l^{\mathrm{a}}$ & $2^{\mathrm{b}}$ \\
\hline Dominance & 34 & 47 & 87 & 84 & 18 & 18 & 02 & 07 & 69 & 68 & 29 & 34 & -03 & 03 \\
\hline Capacity for Status & 32 & 26 & 41 & 35 & 27 & 32 & 12 & 11 & 68 & 70 & 46 & 58 & -02 & -14 \\
\hline Sociability & 67 & 66 & 55 & 68 & 18 & 27 & 02 & 04 & 75 & 78 & 28 & 38 & -06 & -12 \\
\hline Social Presence & 60 & 57 & 48 & 46 & 17 & 22 & -14 & -18 & 63 & 67 & 24 & 26 & -20 & -25 \\
\hline Self-Acceptance & 49 & 48 & 66 & 69 & 05 & 06 & -16 & -16 & 66 & 63 & 32 & 35 & -12 & -16 \\
\hline Independence & 06 & 19 & 57 & 53 & 32 & 39 & 06 & 04 & 70 & 72 & 32 & 37 & -14 & -13 \\
\hline Empathy & 40 & 36 & 39 & 28 & 28 & 35 & -12 & -06 & 52 & 54 & 41 & 44 & -31 & -34 \\
\hline Responsibility & -16 & -07 & 18 & 10 & 40 & 35 & 56 & 59 & 36 & 39 & 41 & 37 & 22 & 32 \\
\hline Socialization & -03 & 04 & 09 & 08 & 54 & 52 & 67 & 73 & 39 & 38 & 19 & 09 & 40 & 44 \\
\hline Self-Control & -44 & -39 & -12 & -17 & 59 & 60 & 71 & 69 & 26 & 29 & 09 & 09 & 42 & 39 \\
\hline Good Impression & -20 & -22 & 14 & -03 & 65 & 60 & 62 & 56 & 45 & 41 & 24 & 17 & 27 & 22 \\
\hline Communality & 16 & 07 & 25 & 21 & 25 & 21 & 26 & 27 & 27 & 28 & 25 & 36 & 17 & 23 \\
\hline Well-Being & 00 & 04 & 29 & 21 & 62 & 67 & 39 & 42 & 71 & 71 & 22 & 22 & 15 & 12 \\
\hline Tolerance & -14 & -18 & 06 & -08 & 54 & 48 & 41 & 38 & 50 & 44 & 33 & 24 & 14 & 12 \\
\hline Achievement via Conformance & -07 & -01 & 35 & 27 & 50 & 55 & 67 & 66 & 50 & 59 & 44 & 39 & 49 & 47 \\
\hline Achievement via Independence & -12 & -19 & 21 & 00 & 38 & 38 & 15 & 22 & 51 & 47 & 52 & 51 & -05 & 09 \\
\hline Intellectual Efficiency & -02 & 01 & 38 & 30 & 45 & 41 & 22 & 15 & 64 & 65 & 62 & 59 & 06 & -02 \\
\hline Psychological-Mindedness & -10 & -06 & 33 & 23 & 46 & 43 & 30 & 21 & 59 & 53 & 45 & 45 & -01 & -01 \\
\hline Flexibility & 14 & 03 & -09 & -23 & 13 & 19 & -37 & -33 & 15 & 17 & 08 & 07 & -65 & -65 \\
\hline
\end{tabular}

Femininity/Masculinity

Vector Scale 2

Vector Scale 3

Managerial Potential

Work Orientation

Creative Temperament

Leadership Potential

Amicability

Law Enforcement Orientation

Tough-Mindedness

Anxiety

Narcissism
Vector Scale 1

\begin{tabular}{rrrrrrrrrrrrrr}
02 & -03 & -38 & -36 & -08 & -06 & 19 & 26 & -31 & -17 & 05 & 17 & 27 & 32 \\
-57 & -66 & -77 & -77 & 10 & 11 & 30 & 26 & -42 & -42 & -26 & -26 & 24 & 24 \\
07 & 08 & 29 & 25 & 28 & 21 & 68 & 63 & 29 & 22 & 18 & 08 & 50 & 57 \\
-08 & -12 & 17 & 10 & 65 & 65 & 32 & 29 & 62 & 60 & 44 & 40 & 02 & -02 \\
00 & 13 & 40 & 31 & 51 & 51 & 36 & 34 & 73 & 75 & 35 & 31 & 19 & 12 \\
-13 & -10 & 16 & 06 & 65 & 73 & 52 & 54 & 59 & 60 & 25 & 23 & 26 & 26 \\
15 & 16 & 16 & 08 & 11 & 10 & -30 & -28 & 39 & 47 & 33 & 41 & $\mathbf{- 5 2}$ & $-\mathbf{5 1}$ \\
21 & 27 & 62 & 58 & 52 & 59 & 39 & 41 & 86 & 85 & 36 & 40 & 18 & 20 \\
-12 & -10 & -08 & -09 & 72 & $\mathbf{7 1}$ & 56 & 55 & 45 & 49 & 14 & 06 & 27 & 22 \\
-02 & 03 & 42 & 48 & 35 & 41 & 34 & 42 & 51 & 44 & -01 & 04 & 26 & 35 \\
-12 & 03 & 41 & 46 & 46 & 51 & 34 & 36 & 64 & 66 & 17 & 22 & 24 & 24 \\
-05 & -12 & -19 & -16 & -47 & -54 & -28 & -32 & -52 & -59 & -15 & -12 & -23 & -08 \\
40 & 47 & 50 & 55 & -45 & -44 & -50 & -49 & -03 & -08 & 03 & -04 & -27 & -18 \\
\hline
\end{tabular}

Note. Decimal points omitted from all correlation coefficients. Coefficients in boldface reflect correlations between scales meant to measure the most similar construct.

${ }^{a}$ College student sample described in Table 2, $N=237$. Correlations greater than .12 are significant at the .05 level; correlations greater than .16 are significant at the .01 level (two-tailed). ${ }^{b}$ College student sample described in Johnson (1996), $N=142$. Correlations greater than .16 are significant at the .05 level; correlations greater than .21, are significant at the .01 level (two-tailed). 
CPI-Prudence is conceptually close to the CPI Socialization (So) scale and shows its highest correlation with So, but also shows strong correlations with Self-Control, Good Impression, and Achievement via Conformance.

CPI-Adjustment shows correlations with virtually all existing CPI scales, although one of its highest correlations is with Well-Being. Gough (1987) regarded overall profile elevation on the CPI as an indicator of general psychological health and self-realization, and it seems that the socioanalytic CPI-Adjustment scale is a good indicator of self-realization. CPI-Intellectance, as expected, showed its highest correlation with Intellectual Efficiency, although it was also related to the other two intellectual achievement scales, Achievement via Conformance and Achievement via Independence. Finally, CPI-Ego Control showed not only the expected, strong, negative correlation with Creative Temperament but also a strong, negative correlation with Flexibility and moderate, positive correlations with Self-Control, Socialization, and Achievement via Conformance.

HPl. The CPI socioanalytic scales were explicit forerunners of scales for the HPI (Hogan, 1986; Hogan \& Hogan, 1992); therefore a comparison of the corresponding scales is in order. Cross-inventory correlations for three different versions of the HPI are presented in Table 6.

Scores from the first version of the HPI (Hogan \& Johnson, 1979) were correlated with the CPI socioanalytic scales for a group of 124 undergraduate students enrolled at the Johns Hopkins University. Convergent correlations across the inventories ranged from $r=.53$ to .74 for the seven scales.

Seventy-five of the 237 college students referred to in Table 2 completed the first published version of the HPI (Hogan, 1986). This version of the HPI collapsed the Ego Control items from the unpublished version into the Prudence scale. Convergent correlations across the inventories ranged from $r=.38$ to .68 .

Finally, 132 participants from a study conducted by Johnson (1996) completed the revised version of the HPI (Hogan \& Hogan, 1992). Convergent correlations range from $r=.35$ to .68 . This version of the HPI split its former Intellectance scale into two narrower scales, corresponding roughly to the "openness" and "intellect" interpretations of FFM Factor V (Johnson, 1994). Names notwithstanding, the new scale retaining the Intellectance label is somewhat closer to the openness conception of Factor $V$ and the new scale called School Success is closer to the intellect version of Factor V (Johnson, 1994). The CPI-Intellectance scale correlated with both new scales, but higher with intellect-based School Success. CPI-Ego Control, on the other hand, shows the expected (negative) correlation with the revised, opennessrelated HPI Intellectance scale.

NEO-PI. The NEO-PI (Costa \& McCrae, 1992) has become a popular way to operationalize the FFM. Costa and McCrae used the NEO-PI to interpret virtually all of the major personality inventories, including the CPI (McCrae, Costa,

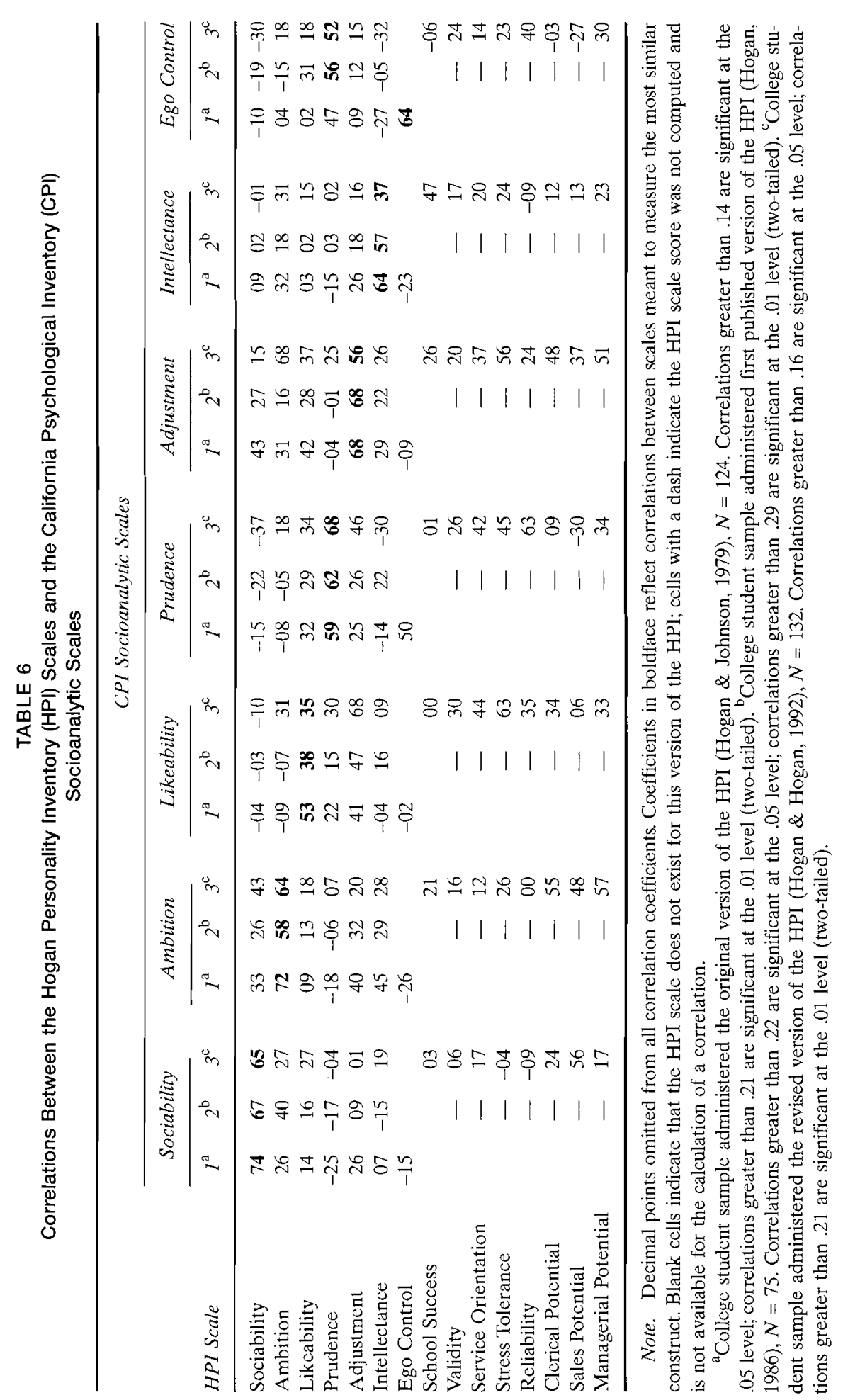


\& Piedmont, 1993). McCrae volunteered to rescore the CPI for the socioanalytic scales for the 348 participants from the McCrae et al. study and to correlate these scores with the standard Extraversion, Agreeableness, Conscientiousness, Neuroticism, and Openness to Experience scales from the NEO-PI. These correlations appear in Table 7.

All of the CPI scales showed convergent but not discriminant validity with the NEO-PI scales. For example, the correlation between CPI-Adjustment and NEO-PI Extraversion was the same magnitude as the correlation between CPI-Adjustment and Neuroticism. This is because socioanalytic theory emphasizes public, social adjustment over private, emotional adjustment (Johnson \& Ostendorf, 1993). Socioanalytic theory regards illness behavior as a disagreeable strategy for attracting attention; hence CPI-Likeability correlates with Neuroticism as well as with Agreeableness. CPI-Ego Control correlates with Conscientiousness as well as (negatively) with Openness; Johnson (1983) explained why this would be expected. Johnson and Ostendorf (1993) and Johnson (1994) further explained exactly how the Hogan and Costa and McCrae conceptions of the FFM converge and diverge, producing the correlational pattern found in Table 7.

Jungian types. Salespersons $(N=44)$ completed the Myers-Briggs Type Indicator (MBTI; Myers, 1962) as part of a personnel selection study. McCrae and Costa (1989) presented data indicating that the MBTI Extraversion (vs. Introversion) scale is strongly related to Factor I; in the present sample CPI-Sociability and CPI-Ambition are correlated in the expected direction (respective $r s=.59$ and .48 , ps <.01). McCrae and Costa also found a significant, but weak, relation between MBTI Extraversion and self-report scores on Factor IV; the socioanalytic Factor IV scale (CPI-Adjustment), which stresses social adjustment, shows a stronger relation $(r=.55, p<.01)$.

McCrae and Costa found the MBTI Intuition-Sensing scale to be related to Factor $\mathrm{V}$; the present data likewise show a correlation between this scale and CPI-Ego Control $(r=-.34, p<.01)$. McCrae and Costa found the MBTI Thinking (vs. Feeling) scale to be inversely associated with Factor II; in the present sample, however, this scale was related only to the Factor V CPI-Intellectance scale ( $r=$ $.31, p<.05$ ). Finally, McCrae and Costa found the MBTI Perceiving (vs. Judging) scale most strongly related to Factor III and somewhat related to self-reports of Factor $\mathrm{V}$; the present data reverse the importance of these factors with correlations of $r=-.35(p<.01)$ with CPI-Prudence and $r=-.71(p<.01)$ with CPI-Ego Control.

Vocational interests. The socioanalytic model (Johnson, 1983) suggests that the high end of Factor I (extraversion) indicates an interest in person-oriented-or what Holland (1979) called Enterprising and Social-occupations,

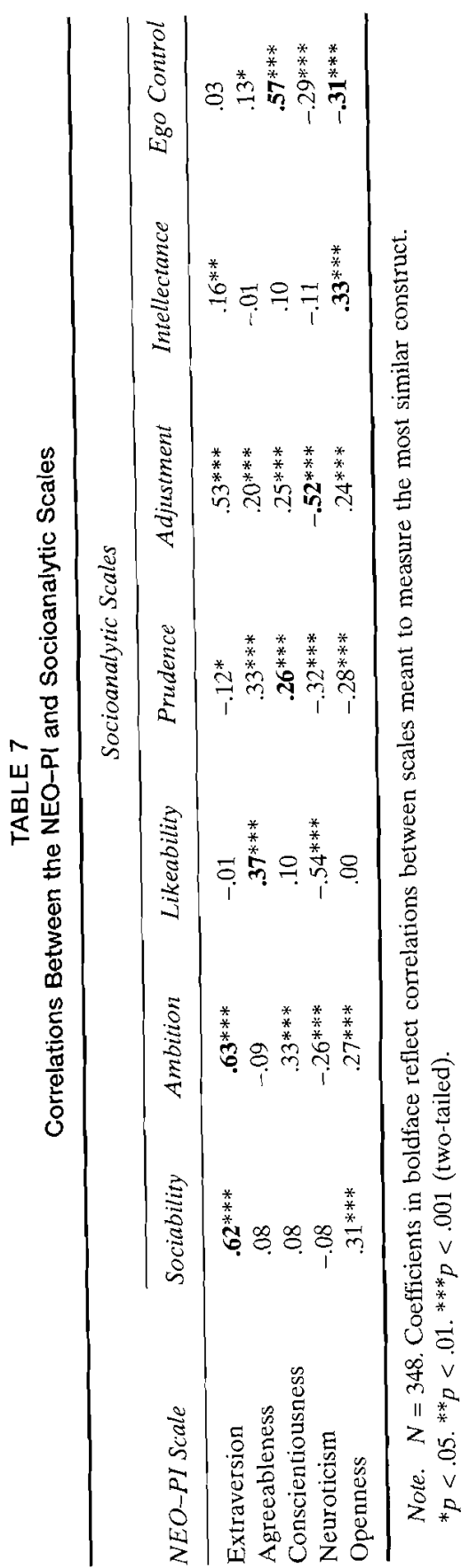


whereas Factor V is related to interest in Holland's Investigative and Artistic occupations. This hypothesis was confirmed by Costa, McCrae, and Holland (1984) and also by data from the salespersons and police officers who completed a measure of Holland's vocational types. CPI-Sociability predicted Holland Social type scores ( $r \mathrm{~s}=.34$ and $.33, p s<.01$ for salespersons and police, respectively) and Enterprising scores $(r s=.33$ and .32 , $p s<.01)$. CPI-Ambition scores also predicted these two types of vocational interests, particularly Enterprising scores, which is expected because Enterprising types seek leadership roles. CPI-Ambition's correlations with Social scores were $r=.21, p<.10$ and $r=.37, p<.01$ for salespersons and police, respectively; this scale's correlations with Enterprising scores were $r=$ .44 and $r=.52, p s<.01$. CPI-Intellectance, but not CPI-Ego Control, predicted Investigative interests $(r s=.52$ and $.37, p s<.01)$ and Artistic interests $(r s=.33$ and $.40, p \mathrm{~s}<.01)$.

Social perceptiveness. The salespersons completed a version of Sarbin and Hardyck's (1955) Stick Figures Test, a measure of social perceptiveness (Johnson, 1981). This scale correlated significantly only with CPI-Intellectance and CPI-Adjustment (both $r s=.34, p<.01$ ), indicating that mere interest in people (sociability and ambition) does not ensure social intelligence.

Moral orientation. Hogan's Survey of Ethical Attitudes (SEA; Hogan, 1970) distinguishes persons with a conservative moral vision from persons who advocate disobedience if their private vision of morality conflicts with social mores. The SEA has already been linked to measures of ego control other than the CPI-Ego Control scale (Johnson, Cheek, \& Smither, 1983; Laufer, Johnson, \& Hogan, 1981). In a sample of 27 male students, SEA scores correlated positively not only with CPI-Ego Control $(r=.39, p<.05)$, but also with CPI-Prudence $(r=.35, p<.05)$ and negatively with CPI-Likeability $(r=-.38, p<.05)$. Moral conservatives are apparently more self-disciplined but less likeable than liberals.

\section{College Activities and School Performance}

The marijuana smokers and principled nonsmokers responded to several items concerning school activities. The reported grade point average of the two groups combined was associated with CPI-Prudence $(r=.21, p<.05)$ and with CPI-Ambition $(r=.19, p<.05)$. When students' majors are coded with the following scoring system: $1=$ humanities, $2=$ social sciences, $3=$ biology/chemistry, $4=$ engineering/physics/mathematics; this code correlated $r=-.28, p<.01$, with CPI-Intellectance; $r=.20, p<.05$, with CPI-Prudence; and $r=.21, p<.05$, with CPI-Ego
Control. This indicates that CPI-Intellectance reflects an intellectual style more typically found in the liberal arts than in the hard sciences and is therefore closer to Norman's (1963) conceptualization of Factor $\mathrm{V}$ as culture rather than quantitative or technical intelligence.

Consistent with findings by Hogan (1989), participation in athletics is associated with CPI-Adjustment $(r=.22, p<.05)$, CPI-Ambition $(r=.27, p<.01)$, CPI-Sociability $(r=.29, p<.05)$, and CPI-Ego Control $(r=.30, p<.01)$. Finally, participation in extracurricular activities generally is a function of CPI-Ambition $(r=.39, p<.01)$ and CPI-Sociability $(r=.29, p<.01)$.

\section{Popularity}

Hogan and Mankin (1970) had a group of 34 male undergraduates from a small, rural junior college participate in work groups of 4 to 5 individuals. Each group had six 75-min meetings; participants were also free to interact with one another between classes. After the last meeting participants were asked to rate the likeability of as many other students in the class as possible on a 7-point scale. Participants had previously taken the CPI. When the CPI was rescored for the socioanalytic scales, rated likeability correlated $r=.42, p<.01$, with the CPI-Likeability scale.

\section{Gender Differences}

The only samples with substantial numbers of both men and women are the college student sample described in Table 2 and a more recently assessed college student sample (Johnson, 1996). In both samples comparisons of mean scores from male and female students indicated trivial differences, generally one raw point or less. $T$ tests showed only one statistically significant difference that replicated across samples. Female students scored higher than male students on CPI-Intellectance, $t(235)=-2.41, p<.05$, and $t(140)=-2.28, p<.05$. This indicates that female students may be somewhat more academically motivated and successful than male students at this particular campus. Whether this difference holds true at other campuses or within noncollege populations remains to be seen.

\section{Job Performance}

Socioanalytic theory has been especially concerned with the impact of personality on job performance (Hogan, 1987; Hogan et al., 1985; Hogan \& Hogan, 1992). Job performance data were available for the Baltimore police and the salesperson 
TABLE 8

Q-sort Correlates of the California Psychological Inventory

Socioanalytic Scales

66 Engineers

45 Scientists

Sociability

15 Is skilled in social techniques of imaginative play, pretending, and humor.

54 Emphasizes being with others; gregarious

48 Keeps people at a distance; avoids close interpersonal relationships.

Ambition

31 Regards self as physically attractive.

75 Has a clear-cut, internally consistent personality

92 Has social poise and presence; appears socially at ease.

55 Is self-defeating.

Likeability

28 Tends to arouse liking and acceptance in people.

88 Is personally charming.

49 Is basically distrustful of people in general;

Prudence

$$
\text { questions their motivations. }
$$

41 Is moralistic.

62 Tends to be rebellious and non-conforming. Adjustment

74 Is subjectively unaware of self-concern; feels satisfied with self.

40 Is vulnerable to real or fancied threat, generally fearful.

68 Is basically anxious

Intellectance

15 Is skilled in social techniques of imaginative play, pretending, and humor

64 Is socially perceptive of a wide range of interpersonal cues.

9 Is uncomfortable with uncertainty and complexities Ego Control

25 Tends toward over-control of needs and impulses; binds tensions excessively; delays gratification unnecessarily.

39 Thinks and associates to ideas in unusual ways; has unconventional thought processes.

82 Has fluctuating moods.

Note. Items modified and reproduced by special permission of the Publisher, Consulting Psychologists Press, Inc., Palo Alto, CA 94303 from California Q-Set by Jack Block, Ph.D. Copyright 1978 by Consulting Psychologists Press, Inc. All rights reserved. Further reproduction is prohibited without the Publisher's written consent.

.24
-.19

.32
-.41

.24

.23

.21

$-.31$

.24

.21

$-.30$

$.07(n s)$

$-.22$

$.09(n s)$

$-.18$

$-.11(n s)$

.25

.23

$-.25$

$-.03(n s)$

20

$-.17$

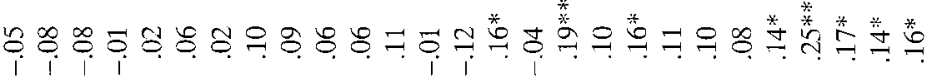

๖ จ

$.24 \quad .32$

o

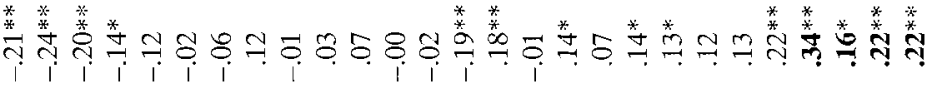

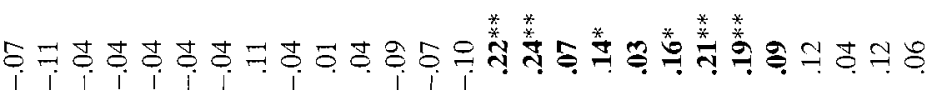

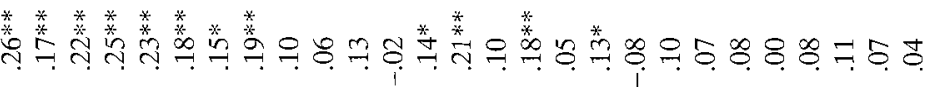

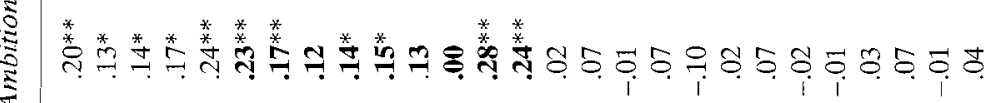

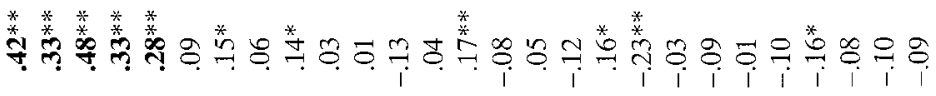

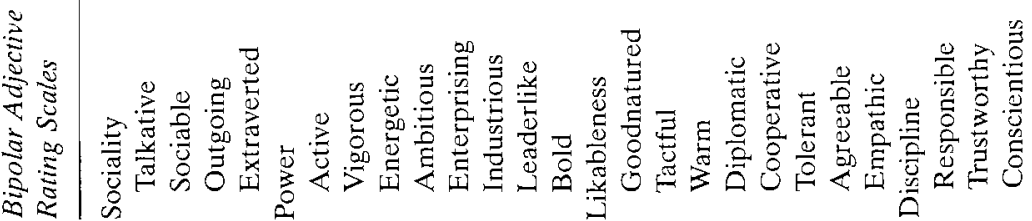




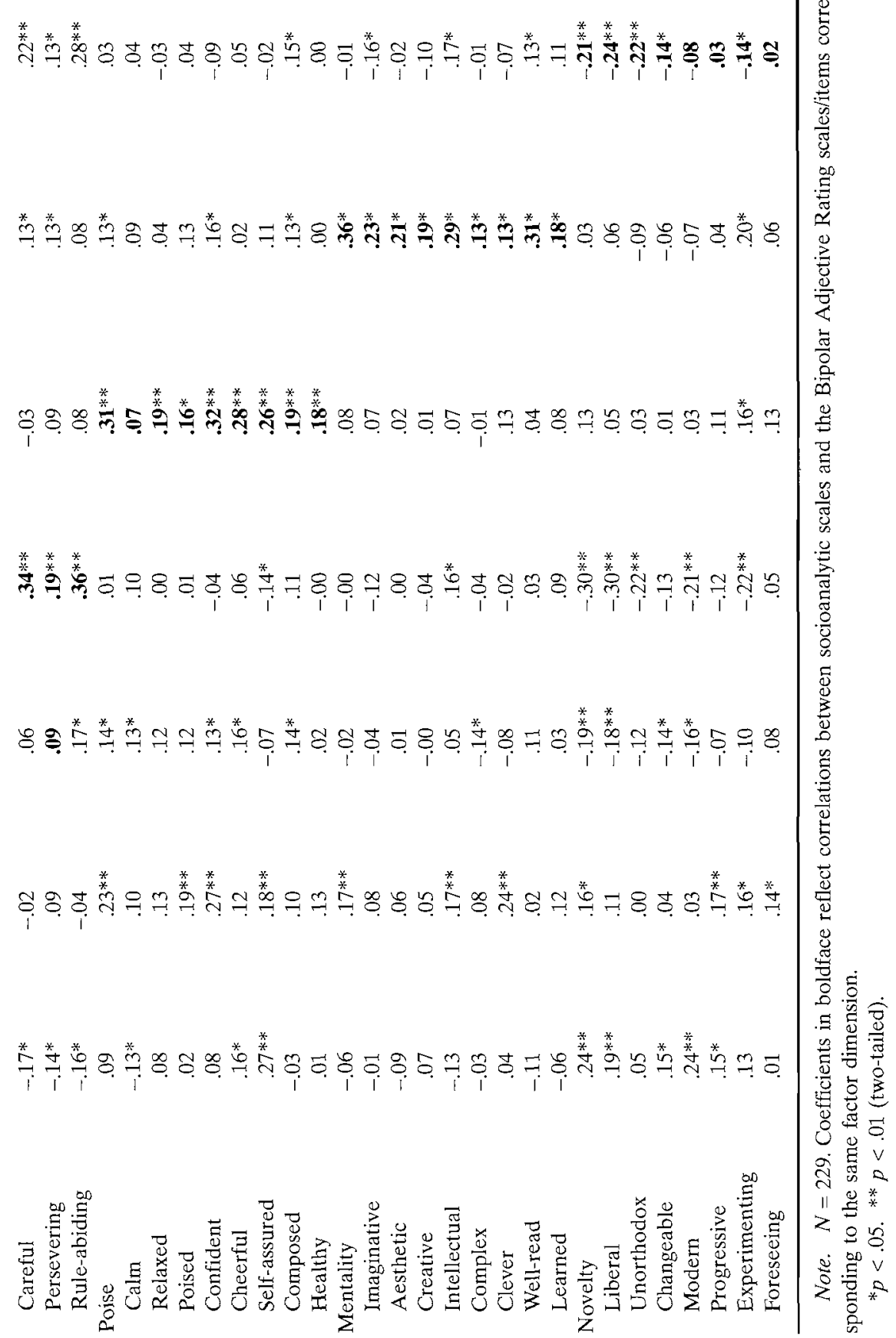

samples. CPI-Ambition predicted grades at the police academy $(r=.24, p<.05)$ and the number of complimentary letters in the officers' files $(r=.37, p<.01)$. CPI-Likeability was inversely related to the number of complaint letters in the officers' files $(r=-.25, p<.05)$. Overall rating performance correlated negatively with CPI-Intellectance $(r=-.24, p<.05)$; as noted before, intelligence rather than intellectuality predicts police performance (Johnson \& Hogan, 1981).

The rate of advancement among salespersons was a function of CPI-Sociability $(r=.25, p<.05)$, CPI-Ambition $(r=.28, p<.05)$, and low CPI-Likeability $(r=$ $-.29, p<.05)$; this highlights a point made by socioanalytic theory: The achievement of status often comes at the expense of low popularity (Hogan, 1983). Hogan's (1979) informal observation that the corporation was a difficult and stressful place to work is borne out by a negative correlation between CPI-Adjustment and the number of years employed with the company $(r=-.31, p<.05)$. Staff ratings for overall performance were related only to CPI-Ambition $(r=.22, p<.10$ for the full sample, and $r=.31, p<.05$ for 26 junior sales personnel).

\section{STEP 4: OBSERVER IMPRESSIONS OF HIGH AND LOW SCORERS}

To provide a sense of how high and low scorers on each scale appear to other people, Table 8 presents some of the items from the California Q-sort (Block, 1978) that correlated significantly with the scale scores for both the engineers and research scientists in the initial scale development sample. Table 9 shows acquaintance trait-rating correlates from the Bipolar Adjective Rating Scales (BARS; Johnson, in press; Johnson, Germer, Efran, \& Overton, 1988) for a group of college students. The BARS is particularly well suited for determining how observers perceive high and low scorers on the socioanalytic CPI scales because the BARS was constructed specifically to measure the same seven-dimensional variant of the FFM.

\section{DISCUSSION}

\section{Summary of Reliability and Validity of the Socioanalytic} Scales

This study introduced a new method of personality scale construction based on the notion that creating specific impressions on personality inventories is a skilled performance (Johnson, 1981; Mills \& Hogan, 1978; Wallace, 1966). This method regards responses to personality items not as descriptive reports of typical behavior, but as speech acts requiring sociolinguistic abilities (cf. the distinction between tests of typical and maximal performance-Dunnette, 1966, p. 64). This method 
requires identifying items that create specific personality impressions of the respondent on a hypothetical audience observing the response.

However accurate the speech act characterization of responding to personality items, the usefulness of this approach needs to be evaluated in terms of the reliability and validity of the resultant scales. The internal consistency reliabilities of the seven socioanalytic scales were modest. CPI-Sociability, CPI-Ambition, and CPI-Adjustment seemed adequately reliable, as did Intellectance, in one sample. Reliability coefficients for CPI-Likeability, CPI-Prudence, and CPI-Ego Control, on the other hand, hovered just below .70, sometimes considered a standard for minimal internal consistency.

The internal consistency coefficients for the socioanalytic scales are similar to those reported for the standard CPI scales (Gough, 1987). Out of 23 coefficients reported for a sample of 400 individuals, three coefficients are less than .60 , four are between .60 and .69 , and another seven are between .70 and .72 . Modest internal consistency coefficients are unproblematic unless they undermine scale validity. The validities of the standard CPI scales are well-established; we turn next to the validities of the new socioanalytic scales.

Correlations between the CPI and parallel HPI scales were in the .60 to .70 range except for the CPI-Likeability scale, which correlated only .35 to .38 with its HPI counterpart. CPI-Likeability also correlated only .37 with the NEO-PI Agreeableness scale. Q-sort observer impressions and acquaintance adjective ratings correlated appropriately with all seven socioanalytic scales. These data indicate that the CPI-Likeability scale possesses some validity, but perhaps not as much as the remaining socioanalytic scales.

\section{Interpretation of Results From a Speech Act Perspective}

The speech act perspective may shed some light on when scales (constructed by any method) might or might not be valid. The speech act perspective says validity requires the personality test-taker and the test interpreter to share the same sociolinguistic rules about item-response meaning. If the respondent fails to see an item as a vehicle for creating an impression on the dimension chosen by the test interpreter, he or she will respond for the wrong reasons. This renders the response irrelevant to the dimension assessed and contributes to error variance.

As the diversity of opinion concerning what kind of statements will be endorsed by persons perceived as sociable, likeable, prudent, and so forth increases, the greater the probability will be that an individual test-taker will respond inappropriately to the items chosen by the test constructor. This would lead to lower internal consistency estimates of reliability, because the respondents are responding according to idiosyncratic reasons instead of according to the dimension chosen by the test constructor. Also, the resultant scale scores will show lower validity in the form of correlations with external criteria.
In the case of likeability, Hogan and Mankin (1970) drew an important distinction between general likeability and clique likeability. General likeability reflects attributes considered likeable by most persons, whereas clique likeability refers to traits uniquely valued by a specific groups of people. Thus, it is possible that persons may say things that make them likeable and popular in their own clique, but disagreeable and unpopular in other groups. A valid Likeability scale must include items that people in general would regard as vehicles for expressing their own likeability.

For the socioanalytic CPI-Likeability scale, Hogan and Johnson (1979) assumed items reflecting concern for others' feelings would create a generally likeable impression on others and items reflecting anger or irritation toward others would create an unlikeable impression. This assumption may have been wrong, or at least incomplete. Hogan and Mankin (1970), for example, found rated likeability to be related to endorsing statements about social poise, verve, self-assurance, tolerance, and tact. Costa and McCrae (1992) suggested that likeable people describe themselves as trusting, straightforward, altruistic, noncombative, modest, and sympathetic. Some participants in this study might have expressed their likeability more accurately if the CPI-Likeability scale had included items with Hogan and Mankin's or Costa and McCrae's themes.

Johnson (1993) tested empirically the notion that shared sociolinguistic knowledge of item response meaning increases item validity. In this study the degree to which raters agreed about item response meaning correlated significantly with the item's ability to predict acquaintance ratings on all factors of the FFM except Factor III (Prudence). Shared sociolinguistic knowledge seemed particularly important for the validity of items assessing the Factor I (sociability) and Factor II (likeability) domains. This suggests that scale constructors might assess pilot items' abilities to generate consensus regarding the items' meanings on a test audience.

\section{The CPI and the FFM}

The evident success of the FFM (McCrae \& John, 1992), especially McCrae and Costa's program of interpreting nearly every widely-used inventory in FFM terms, might be viewed by some as a call to abandon older conceptualizations of personality, including previous scoring keys for the CPI. However, the scales described here are in no way intended to replace the standard scales of the CPI. They were constructed, rather, in the spirit of Gough's (1987) description of the CPI as an "open system," subject to reorganization, reconceptualization, and revision. Researchers interested in scoring CPI protocols for Hogan's view of the FFM now have a means for doing so.

No claim is being made here that the socioanalytic scales for the CPI assess the FFM, for there are several slightly different versions of the FFM (Johnson \& Ostendorf, 1993). Furthermore, these scales are not the only way to derive FFM 
scores from the CPI. Other schemes for extracting the FFM from the CPI are available. Gough's (1987) cuboid model appears to be based on Factors I, III, and IV. Gough (personal communication, September 12, 1995) also suggested that the existing Sociability, Amicability, Socialization, Well-Being, and Creative Temperament scales provide perfectly reasonable approximations of the FFM. Correlations between these five standard CPI scales and the socioanalytic scales (Table 5) support that suggestion. Robert R. McCrae (personal communication, August 20,1993 ) is collaborating with Oliver John on new FFM scales for the CPI. How are these alternatives likely to differ from the present socioanalytic scales?

The difference between the present scales and Gough's lie in item content. Gough's empirical approach identifies items whose manifest content may or may not be obviously related to the five factors. McCrae's rational approach will also show some differences from the approach described here because his view of the FFM differs from Hogan's (see Johnson \& Ostendorf, 1993). The following illustration underscores the differences between Hogan's and McCrae's conceptualization of Factor III and between the speech act and rational approaches to scale construction.

Hogan's view of Factor III emphasizes moral rectitude, impulse control, and nondelinquency; McCrae's view concerns organized purposefulness (which Hogan sees as part of ambition). Hogan recognizes that delinquents rarely express positive attitudes toward authority (Johnson, Hogan, Zonderman, Callens, \& Rogolsky, 1981). Therefore, someone who fails to endorse CPI item number 125 , "There is something wrong with a person who can't take orders without getting angry or resentful" (CPI Form 462, item number 125; Gough, 1986) might be regarded as an imprudent delinquent. From a speech act perspective, this is clearly a Factor III (Prudence) item. McCrae et al. (1993), on the other hand, viewed this item as unrelated to all of the five factors because its manifest content does not refer to any of the five factors. The rational approach views item responses as disinterested descriptions of behavior rather than performances that have effects on observers.

\section{Item Response Performance and Job Performance}

The estimation of police effectiveness and sales success were offered as examples of how the socioanalytic scales can be used to predict job performance. The magnitude of the correlations between the scale scores and performance criteria are typical for such data, suggesting that these scales are no better or no worse than other well-developed personality scales for actuarial prediction. The advantage of scales developed from the speech act perspective lies, rather, with increasing our understanding of why checkmarks on paper-and-pencil inventories predict real-life job performance. If creating favorable impressions via item responses is indeed a skill analogous to creating favorable impressions in the workplace that lead to high job performance ratings, it is no longer surprising that personality test scores predict job performance. To investigate these ideas, measures of sociolinguistic skill need to be developed. We can then investigate whether personality scores from persons with low sociolinguistic skill are less valid than scores from persons with high sociolinguistic skill. If this hypothesis is confirmed, that is, if sociolinguistic skill moderates personality scale validity, measures of this skill would be useful in applied settings.

In an earlier exposition of the speech act approach (Johnson, 1986), I described the cognitive skills and knowledge necessary for a job applicant to present favorably on a personality test during an employment interview. First, the applicant must possess accurate knowledge about the personality traits regarded by the employer as relevant for that job. Second, the applicant must know how to respond to each personality item in order to elevate (or depress) his or her score on the relevant trait dimensions. Such sociolinguistic knowledge is at least partially implicit, much as our syntactic knowledge for producing grammatically correct speech is implicit. I found (Johnson, 1986) that conscious attempts to create favorable scores can lead to scores less favorable than those gathered under unself-conscious conditions, although a later study showed that conscious self-enhancement may sometimes lead to more favorable scores (Johnson, 1987). The precise conditions under which self-consciousness affects the validity of personality scores may be clarified with additional research guided by the speech act perspective.

\section{ACKNOWLEDGMENTS}

This article is based on an invited paper presented to the psychology department of the University of Groningen while I was a visiting research fellow at the University of Bielefeld, supported by a fellowship from the Alexander von Humboldt-Stiftung.

I thank Alois Angleitner and Robert Wicklund for their help in arranging my research stay and to the psychology department at Bielefeld and the von HumboldtStiftung for their support during that time. Thanks also go to Harrison G. Gough, Robert Hogan, and Robert R. McCrae for their helpful comments on earlier versions of this article and to Robert R. McCrae for providing the correlations between the CPI and NEO-PI.

\section{REFERENCES}

Block, J. (1978). The Q-sort method in personality assessment and psychological research. Palo Alto, CA: Consulting Psychologists Press.

Block, J. H., \& Block, J. (1980). The role of ego control and ego resiliency in the organization of behavior. In W. A. Collins (Ed.), Development of cognition, affect, and social relations: The Minnesota symposium on child psychology (Vol. 13, pp. 39-101). Hillsdale, NJ: Lawrence Erlbaum Associates, Inc.

Costa, P. T., Jr., \& McCrae, R. R. (1985). The NEO Personality Inventory manual. Odessa, FL: Psychological Assessment Resources. 
Costa, P. T., Jr., \& McCrae, R. R. (1992). Revised NEO Personality Inventory (NEO PI-R $R^{T M}$ ) and NEO Five-Factor Inventory (NEO-FFI): Professional manual. Odessa, FL: Psychological Assessment Resources.

Costa, P. T., Jr., McCrae, R. R., \& Holland, J. L. (1984). Personality and vocational interests in an adult sample. Journal of Applied Psychology, 69, 390-400.

Dunnette, M. D. (1966). Personnel selection and placement. Belmont, CA: Wadsworth.

Dunnette, M. D., Wernimont, P., \& Abrahams, N. (1964). Further research on vocational interest differences among several types of engineers. Personnel and Guidance Journal, 42, 484-493.

Gough, H. G. (1975). Manual for the California Psychological Inventory. Palo Alto, CA: Consulting Psychologists Press.

Gough, H. G. (1986). California Psychological Inventory, Form 462. Palo Alto, CA: Consulting Psychologists Press

Gough, H. G. (1987). CPI administrator's guide. Palo Alto, CA: Consulting Psychologists Press.

Gough, H. G., \& Woodworth, D. G. (1960). Stylistic variations among professional research scientists. Journal of Psychology, 49, 87-98.

Grundy, P. (1995). Doing pragmatics. NY: Arnold.

Hansson, R. O., Hogan, R., Johnson, J. A., \& Schroeder, D. (1983). Disentangling Type A behavior: The roles of ambition, insensitivity, and anxiety. Journal of Research in Personality, 17, 186-197.

Hogan, J. (1989). Personality correlates of physical fitness. Journal of Personality and Social Psychology, 56, 284-288.

Hogan, R. (1970). A dimension of moral judgment. Journal of Consulting and Clinical Psychology, 35 , 205-212.

Hogan, R. (1971). Personality characteristics of highly rated policemen. Personnel Psychology, 24, 679-686.

Hogan, R. (1976). Personality: The personological tradition. Englewood Cliffs, NJ: Prentice-Hall.

Hogan, R. (1979). Development of a selection battery for operating specialists. Unpublished report, Personnel Assessment and Selection Service, Inc., Baltimore, MD

Hogan, R. (1983). A socioanalytic theory of personality. In M. M. Page (Ed.), Nebraska symposium on motivation 1982: Personality-current theory and research (pp. 55-89). Lincoln: University of Nebraska Press.

Hogan, R. (1986). Hogan Personality Inventory manual. Minneapolis, MN: National Computer Systems.

Hogan, R. (1987, August). Conceptions of personality and the prediction of job performance. Paper presented at the meeting of the American Psychological Association, New York.

Hogan, R., Carpenter, B. N., Briggs, S. R., \& Hansson, R. O. (1985). Personality assessment and personnel selection. In H. J. Bernardin \& D. A. Bownas, (Eds.), Personality assessment in organizations (pp. 21-52). New York: Praeger.

Hogan, R., \& Hogan, J. (1992). Hogan Personality Inventory manual. Tulsa, OK: Hogan Assessment Systems.

Hogan, R., \& Johnson, J. A. (1979). The Hopkins Personality Inventory: A socioanalytic view of the structure of personality. Unpublished manuscript, The Johns Hopkins University, Baltimore, MD.

Hogan, R., \& Johnson, J. A. (1981, September). The structure of personality. Paper presented at the meeting of the American Psychological Association, Los Angeles.

Hogan, R., \& Mankin, D. (1970). Determinants of interpersonal attraction: A clarification. Psycholugical Reports, 26, 235-238.

Hogan, R., Mankin, D., Conway, J., \& Fox, S. (1970). Personality correlates of undergraduate marijuana use. Journal of Consulting and Clinical Psychology, 35, 58-63.

Hogan, R., \& Weiss, D. S. (1974). Personality correlates of superior academic achievement. Journal of Counseling Psychology, 21, 144-149.
Holland, J. L. (1979). The Self-Directed Search professional manual. Palo Alto, CA: Consulting Psychologists Press.

Johnson, J. A. (1981). The "self-disclosure" and "self-presentation" views of item response dynamics and personality scale validity. Journal of Personality and Social Psychology, 40, 761-769.

Johnson, J. A. (1983). Criminality, creativity, and craziness: Structural similarities in three types of nonconformity. In W. S. Laufer \& J. M. Day (Eds.), Personality theory, moral development, and criminal behavior (pp. 81-105). Lexington, MA: D. C. Heath.

Johnson, J. A. (1986, August). Can job applicants dissimulate on personality tests? Paper presented at the meeting of the American Psychological Association, Washington, DC.

Johnson, J. A. (1987, August). Dissembling on the Hogan Personality Inventory during simulated personnel selection. Paper presented at the meeting of the American Psychological Association, New York

Johnson, J. A. (1993). The impact of item characteristics on item validity. Unpublished manuscript, Pennsylvania State University, DuBois Campus.

Johnson, J. A. (1994). Clarification of factor five with the help of the AB5C model. European Journal of Personality, 8, 311-334

Johnson, J. A. (1996, July). Predicting observers' ratings of the big five from self-report inventories. Paper presented at the Eighth European Conference on Personality, Ghent, Belgium.

Johnson, J. A. (in press). Interpreter's guide to the Bipolar Adjective Rating Scales (BARS). Palo Alto, CA: Mind Garden.

Johnson, J. A., Cheek, J. M., \& Smither, R. (1983). The structure of empathy. Journal of Personality and Social Psychology, 45, 1299-1312.

Johnson, J. A., Germer, C. K., Efran, J. S., \& Overton, W. F. (1988). Personality as the basis for theoretical predilections. Journal of Personality and Social Psychology, 55, 824-835.

Johnson, J A. \& Hogan, R. (1981). Vocational interests, personality, and effective police performance. Personnel Psychology, 34, 49-53.

Johnson, J. A., Hogan, R., Zonderman, A. B., Callens, C., \& Rogolsky, S. (1981). Moral judgment, personality, and attitudes toward authority. Journal of Personality and Social Psychology, 40, 370-373.

Johnson, J. A., \& Horner, K. L. (1990, March). Personality inventory item responses need not veridically reflect "actual behavior" to be valid. Paper presented at the meeting of the Eastern Psychological Association, Philadelphia.

Johnson, J. A., \& Ostendorf, F. (1993). Clarification of the five factor model with the abridged big five-dimensional circumplex. Journal of Personality and Social Psychology, 65, 563-576.

Lanning, K., \& Gough, H. G. (1991). Shared variance in the California Psychological Inventory and the California Q-Set. Journal of Personality and Social Psychology, 60, 596-606.

Laufer, W. S., Johnson, J. A., \& Hogan, R. (1981). Ego control and criminal behavior. Journal of Personality and Social Psychology, 41, 179-184.

McCrae, R. R., \& Costa, P. T., Jr. (1985). Openness to experience. In R. Hogan \& W. H. Jones (Eds.) Perspectives in personality (Vol. 1, pp, 145-172). Greenwich, CT: JAl.

McCrae, R. R., \& Costa, P. T., Jr. (1989). Reinterpreting the Myers-Briggs Type Indicator from the perspective of the five-factor model of personality. Journal of Personality, 57, 17-40.

McCrae, R. R Costa P. T J \& \& Piedmont, R. L (1993). Folk concepts, natural language, and psychological constructs: The California Psychological Inventory and the Five-Factor Model. Journal of Personality, $61,1-26$.

McCrae, R. R \& John, O P (1992) An introduction to the five-factor model and its applications. In R. R. McCrae (Ed), The five-factor model: Issues and applications [Special issue]. Journal of Personality, 60, 175-215

Mead, G. H. (1934). Mind, self and society. Chicago: University of Chicago Press. 
Meehl, P. E. (1945). The dynamics of "structured" personality tests. Journal of Clinical Psychology, 1 , 296-303.

Mills, C., \& Hogan, R. (1978). A role-theoretical interpretation of personality scale item responses. Journal of Personality, 46, 778-785.

Myers, 1. B. (1962). Munual for the Myers-Briggs Type Indicator. Princeton, NJ: Educational Testing Service.

Norman, W. T. (1963). Toward an adequate taxonomy of personality attributes: Replicated factor structure in peer nomination personality ratings. Joumal of Abnormal and Social Psychology, 66, 574-583.

Rorer, L. G. (1990). Personality assessment: A conceptual survey. In L. A. Pervin (Ed.), Handbook of personality: Theory and research (pp. 693-720). New York: Guilford.

Sarbin, T. R., \& Hardyck, C. D. (1955). Conformance in role perception as a personality variable. Journal of Consulting Psychology, I9, 109-111.

Searle, J. R. (1969). Speech acts: An essay in the philosophy of language. London: Cambridge University Press.

Wallace, J. (1966). An abilities conception of personality: Some implications for personality measurement. American Psychologist, 21, 132-138.

Welsh, G. S. (1975). Creativity and intelligence: A personality approach. Chapel Hill, NC: Institute for Research in Social Science.

White, R. W. (1959). Motivation reconsidered: The concept of competence. Psychological Review, 66, 297-333.

\section{APPENDIX}

\section{Scoring Key for California Psychological Inventory Socioanalytic Scales}

CPI-Sociability. True: 1, 4, 52, 102, 163, 167, 168, 208, 218, 231, 239, 242, 251, 296, 319, 395. False: $83,87,188,215,249,318, \mathbf{3 4 0 .}$

CPI-Ambition. True: 6, 53, 112, 171, 179, 202, 216, 224, 256, 260, 264, 320, 346, 359, 376, 380, 403, 412, 448. False: 7, 31, 145, 379, 385, 422, 426, 443.

CPI-Likeability. True: 45, 127, 198. False: 29, 44, 56, 57, 71, 81, 94, 137, 153, 161, 233, 270, 290 , $\mathbf{2 9 3}, 342, \mathbf{3 6 4}, 374,428$.

CPI-Prudence. True: 125, 149, 165, 174, 181, 212, 223, 314, 367. False: 77, 93, 101, 185, 214 , 250, 275, 288, 302, 336, 396, 420, 431.

CPI-Adjustment. True: 21, 108, 200, 245, 259. False: 12, 38, 40, 54, 76, 111, 124, 150, 159, 176, 177, 186, 225, 227, 232, 257, 258, 284, 416, 418, 419, 429, 452 .

CPI-Intellectance. True: $8,17, \mathbf{5 0}, 61,84,97,140, \mathbf{1 5 2}, 160,166,228,269,280,283,292,391$.

False: 121, 199, 281, 311, 352, 382, 401, 436.

CPI-Ego Control. True: 14, 24, 35, 85, 88, 229, 230, 246, 328, 361, 363, 387, 408. False: 99, 119, 132, 143, 157, 170, 331, 456 .

Note. Core items identified by Hogan and Johnson (1979) are in boldface. Item numbers are from California Psychological Inventory, Form 462, by Harrison G. Gough, 1986, Palo Alto, CA: Consulting Psychologists Press. Copyright 1986 by Consulting Psychologists Press, Inc. Reprinted with permission. 